\title{
DEVELOPMENT OF SLOW TOURISM CHALLENGE AND OPERATION ARCHITECTURE: A CASE STUDY ON GREEN ISLAND, TAIWAN
}

\author{
Ren-Fang CHAO \\ Department of Leisure Management, I-Shou University, No. 1, Sec. 1, Syuecheng Rd., \\ Dashu District, Kaohsiung City 84001, Taiwan, R.O.C. \\ E-mail:rfchao@isu.edu.tw
}

\begin{abstract}
Slow tourism, a sustainable tourism pattern gradually emphasized over the past years, stresses on experiencing tourism campaigns with slow and recreational attitudes to create value for life and enhance well-being. Although the concept of slow tourism presents certain consensus in academic studies, it still encounters a lot of operational challenges, which could be properly solved through the educational training of operators and consumers and the economic value chain formed by industry alliances. In terms of the practical operation, the slow tourism promotion architecture is developed for promoting slow tourism in Green Island, Taiwan. The architecture is divided into two stages. The preparation stage focuses on communication, training, and the improvement of industrial environment to form the slow tourism industry alliance for cross-selling and importing visitors. The operational stage tends to form the overall image of the destination by maintaining the quality of slow tourism through review and innovation and gradually extend the slow tourism industry alliance. The key role in the promotion architecture is local intermediary organizations which integrate internal and external resources to have slow tourism present the maximal benefits.
\end{abstract}

Keywords: sustainable tourism, tourism education, strategic alliance, intermediary organization, tourism marketing

\section{INTRODUCTION}

Sustainable tourism is based on the concept of sustainable development. For current societies, the specific goals and strategies are essential for the sustainable development, where economy, society, and natural ecosystem are closely linked (Golusin and Ivanović 2009). Sustainability is also regarded as a concept or living style, with which economy, environment, and society could be includ- 
ed. Sustainable development aims to stress on the connotation of human beings pursuing welfare in current generation but not sacrificing the opportunities of the descendants pursuing welfare (Katircioglu 2009). Based on the concept of sustainable development, sustainable tourism also emphasizes the dimensions of economy, society, and ecology (Aall 2014) and the benefits cross generations. The correlations could be found out in the definition of sustainable tourism. According to World Tourism Organization, "Tourism that takes full account of its current and future economic, social and environmental impacts, addressing the needs of visitors, the industry, the environment and host communities" (World Tourism Organization Network 2014).

Although there is definite consensus about the concept of sustainable development, the specific practice is rather difficult (Volkery et al. 2006). Sustainable tourism encounters similar problem. Aiming at the questions of how travel patterns conformed to the requirements of sustainable tourism and whether the operation of such tourism could achieve the anticipated goals, Bâc (2013) proposed four sustainable tourism patterns of ecotourism, pro-poor tourism, volunteer tourism, and slow tourism. As a matter of fact, such four sustainable tourism patterns were the changes in the practical operation of sustainable tourism. Since Hetzer (1965) proposed the concept of ecotourism, the ideas of pro-poor tourism, volunteer tourism, and slow tourism have been discussed (Beeton 2006; Weaver 2006; Heitmann et al. 2011), and slow tourism could be the complex. Viewing from the development process, such four sustainable tourism patterns present obvious phased development. The concept of slow tourism was originated from slow food movement (Hall 2006), but the core concept is to receive a high-quality experience (Heitmann et al. 2011). Besides, slow tourism also covers the issues of mental slowness, tourist experience, and environmental awareness (Lumsdon and McGrath 2011; Li et al. 2014). In spite that slow travel is originated from the concept of slow food, it becomes an economic style after absorbing travel elements, reduces the destruction to the environment by integrating the concept of environmental awareness, and decreases the social impact on tourism development by the favorable interaction with local citizens in touring spots (Chang 2014). Therefore, such concepts of slow tourism could become the operation strategies of sustainable tourism through appropriate travel element changes. Moreover, the proper development of slow tourism could effectively improve the impact caused by mass tourism and promote the quality in tourism (Djeri et al. 2014). The researcher therefore considers slow tourism as a new sustainable tourism pattern.

Similar to the practice of sustainable development, Bâc admitted the operational problems of slow tourism, in which the enhancement of consumer participation rate was the major challenge. Although slow tourism is still at the concept 
development stage (Lumsdon and McGrath 2011), it is an effective way to promote sustainable development.

Past research on slow travel focused more on theoretical exploration (Lumsdon and McGrath 2011), but less on actually operating cases. Following the concept of slow travel, slow travel was regarded as a sustainable tourism model in Green Island of Taiwan in 2013 so that the practice of slow travel was well confirmed and the promotion structure of community-based slow travel was concluded in the development process. The data in the process of Green Island developing slow travel are collected through participant observation, and interviews and literature analyses are utilized for understanding the contexts and the operational structure of Green Island developing slow travel. This study aims to use the promotion structure of slow travel in Green Island for the reference of other regions developing slow travel as well as the basis for successive research on slow travel.

In this study, the development process and concept of slow tourism is first reviewed, and the practical operational problems of slow tourism are critically proposed for feasible solutions. Furthermore, from the case analysis of the slow tourism promotion in Green Island, Taiwan, the operation process and the actual benefits are applied to developing the slow tourism promotion pattern ( $\mathrm{Fu}$ and Yeh 2014).

\section{THE CONCEPT OF SLOW TOURISM}

A lot of researchers supported the effects of slow food movement on slow tourism (Aall 2014; Bâc 2013; Dickinson and Lumsdon 2010; Hall 2006; Timms and Conway 2011). In addition to the dissatisfaction with and the accusation of fast food, slow food movement primarily opposed the standardization of savor and culture (Bâc 2013). It required time to dig out the connotation and value of the savor of tourism. Accordingly, Aall (2014) regarded that "the principle idea behind slow tourism is to take time to savor experiences".

In the society with rapid pace of life, people are unconsciously tied by "time"; the philosophy of slow life is then created in the introspection of the pace of life. The effects of slow life have slow tourism gradually be emphasized.

\subsection{Rebuilding the rhythm of time: Inspiration of slow tourism}

After entering the industrial era, the pursuit of speed and efficiency was linked with human life. The Taylor effect, induced by the pursuit of work efficiency in the $19^{\text {th }}$ century, had people start to live in the pressure of time (Levine 1997; 
Erhart 2008). After the end of World War II, a lot of countries crazily pursued development, from which faster speed resulted and even intruded in human life. Blindly pursuing speed resulted in people being anxiously constrained by time. Some people stubbornly considered the flow of time, which could be caught up by constantly quickening the pace. Dossey (1982) therefore created Time Disease. Comparing to modern societies, there must be a lot of people suffering from time diseases.

To respond to the constantly increasing time pressure, the anticipation of more time (especially free time) is enhanced that many people expect to have sufficient time to proceed significant affairs, which are normally regarded as significant and primary (Reisch 2001). Little by little, the resistance to time pressure is emphasized by people.

Carlo Petrini, the retarded motion advocate of the resistance to time pressure and the originator of slow food movement, mentioned that slow life was the power to control the rhythm of personal life and to strive for personal pace (Honoré 2010). In other words, slow life did not mean to simply slow down the speed, but was a cultural revolution to encourage people building the relationship with others, to tightly integrate with life, work, and food, and to become the master of time (Giudici and Dessì 2011). For this reason, slow life orientated to apply proper speed, focus on quality, not quantity (Honoré 2010), and allow people present creativity on the work, recreation, family, and society (Parkins 2004). Regarding the living value, slow life could create meanings for life. Under the fundamental concept of slow life, slow tourism intends to create meanings for tourism.

\subsection{Connotation of slow tourism}

In face of the impact from mass tourism, the sustainable tourism with reducing environmental impact has been sought over the past years. Based on the similar reason, Bâc (2013) proposed four sustainable tourism patterns, which were expected to maintain or improve local conditions of environment, culture, or social economy (Conway and Timms 2010). In comparison with other sustainable tourism patterns, slow tourism, originated from slow life, was close to human anticipation of life. Looking for the value of life in free time required in recreation was similar to Godbey's definition of recreation that recreation was a relatively free life got out of the external pressure of cultural environment and material environment, allowed an individual move with personally favored and instinctively perceived value, and provided a basis for the belief (Godbey 2003). In this case, tourism, as a recreational pattern, could highlight the meaning from the value of life dug in the tourism process. 
Slow tourism is based on retarded life to make the tourism be really relaxing (Gardner 2009), enjoy happiness in discovery, learning, and sharing, and create the opportunities to interact and connect with local people at the destination when the pace was slowed down on holidays (Heitmann et al. 2011). Woehler (2004), based on recreation, joy, local emotion, and relationship with local people, therefore focused on preventing local features from being damaged.

Slow tourism also concerns about the effects of transportation on environments (Ceron and Dubois 2007; Gössling et al. 2008; Molz 2009), especially the carbon emission problem in tourism. Any transportation could appear significant greenhouse gas emission in a long distance (such as 1000 miles) move (Peeters and Schouten 2006). Since the greenhouse gas emission from airplanes is obviously higher than from other transportation, slow tourism movers would normally avoid taking airplanes. Nonetheless, avoiding taking airplanes would restrict the choice of tourism and result in the conflict between travel decisions. Dickinson et al. (2011) proposed the factors of environmental awareness, activity pattern, and tourist experience in choosing tourism patterns and classified slow travelers as "hard slow travelers" and "soft slow travelers". Hard slow travelers stressed more on environmental awareness than on activity patterns and tourist experiences, while soft slow travelers focused more on activity patterns and tourist experiences, in spite of avoiding engaging in high carbon emission activities and behaviors. Comprehensively, Gardner proposed the following characters of slow tourism (Gardner 2009).

- Slow tourism is a state of mind.

- Tourists should travel slow and avoid aircraft.

- The journey is intrinsic to the tourism experience.

- Locality is important.

- Slowing down to enjoy the city or the landscape is a key element.

- Culture through language and engagement with local people makes for a better holiday.

- Tourists should make opportunities by seeking out the unexpected.

- Giving back to local communities is integral.

Aiming at Gardner' slow tourism characters, Lumsdon and McGrath (2011) further explained that the connotation of the value of slowness and time, location and activity objectives, transportation and tourist experience patterns, and environmental awareness in slow tourism should be carefully considered. With the grounded theory oriented research, Lumsdon and McGrath (2011) made the following conclusion of slow tourism.

Slow tourism is a sociocultural phenomenon, focusing on holiday making but also on day leisure visits, where use of personal time is appreciated differently. Slowness is valued, and the journey is integral to the whole experi- 
ence. The mode of transport and the activities undertaken at a destination enhance the richness of the experience through slowness. Whilst the journey is the thing and can be the destination in its own right, the experience of locality counts for much, as does reduced duration or distance of travel.

Under the definition of slow tourism, the difference from other sustainable tourism patterns is questioned. Bâc (2013) proposed four sustainable tourism patterns of ecotourism, pro-poor tourism, volunteer tourism, and slow tourism but did not discuss the relations. However, it was found from the connotation that such four patterns presented phased development. In other words, the changes of societies and the evolution of people' concept of environment also revealed the phased development on the practice and concept of sustainable tourism. Conway and Timms (2010) proposed the concept of Holistic Umbrella to further explain the role of slow tourism in sustainable tourism. He pointed out slow tourism as an alternative tourism integrating ecotourism, pro-poor tourism, agricultural tourism, heritage tourism, and community tourism. In other words, slow tourism, as a travel pattern developed from the inspiration of slow life, absorbed the connotation of several sustainable tourism patterns, the economic value in tourism, the travel attitudes towards low carbon and environmental protection, and the feedback to the traveled communities are covered to form the travel pattern to create self-value. Since slow travel presents the features of other sustainable tourism, so slow tourism could be regarded as a complex of various sustainable tourism patterns.

\section{CHALLENGE TO SLOW TOURISM}

Similar to the practice of many theoretical concepts, a lot of operational dilemmas are often encountered when transforming theories into practical actions. Slow tourism shows no exception. Even though the definition of slow tourism has been clearly realized, operational dilemmas could still occur in practice. Especially, enhancing the consumer participation rate is the major challenge to the operation of slow tourism (Bâc 2013). Moreover, two major problems also exist in the slow tourism promotion, including persuading visitors into participating in slow tourism itineraries and making slow tourism become the major development of tourism economy (Mair 2011). Two questions are concluded for such problems, covering the education to change both operators' and consumers' concepts of slow tourism and the construction of slow tourism industry chain. 


\subsection{Education of slow tourism: operators and consumers as the subjects}

The practice of slow tourism requires the match between tourism operators and consumers to generate economic opportunities. Although the challenge to enhance the consumer participation rate in slow tourism is proposed (Bâc 2013), the consumer participation and the travel operators' concepts and skills of slow tourism are closely related.

From the aspect of human resources, the cultivation of sustainable tourism operation talent is a process to achieve the anticipated goals of sustainable tourism (Hatipoglu et al. 2014). Different from the slow tourism education in school systems, the operators of slow tourism, as the alternative of mass tourism, originally engaged in mass tourism. For this reason, it is important to trigger the operators' learning motivation. Practically, two preparations are required for inducing slow tourism operators to accept the educational training. First, the construction of slow tourism vision allows the operators believing that slow tourism could surely maintain the original economic income and is an environment-friendly tourism pattern. In the operation process, demonstration travel, in addition to general educational propaganda, allows the potential operators believing in the feasibility of slow tourism. Second, the slow tourism materials derived from local knowledge systems are regarded as the medium to promote slow tourism. The combination with local knowledge systems is a key success factor in the development of sustainable tourism (Reyes-Garcia et al. 2013). The value of utilizing local knowledge lies in constructing local cultural identification and creating unique slow tourism elements locally.

The consumer education of the activity experiencing process is mainly applied to the process. The operator interprets the activity meaning and value to consumers, who experience the meaning of environmental sustainability in the process and commonly contribute to the sustainable development of touring spots.

The consumer education during the tour tends to have the operators lead consumers to enjoy the value of slow tourism through "share" and "experience" so as to construct the consumers' concepts of slow tourism. Since slow tourism operators have intervened in the choice of local travel elements in the training process and integrated the living experiences with local knowledge systems, the operators present powerful appeal to the consumers with the slow tourism sharing and experiences. It is a good way to have consumers accept the concept of slow tourism.

Although the slow tourism education for operators and consumers are distinct, there are mutual influences in between. The past research proved that consumers would affect operators' opinions and further influence the motivation to invest in the tourism operation (McGehee and Andereck 2009). Consequently, operators and consumers could be the learning partners in the slow tourism learning to make the region move forward to the sustainable development. 


\subsection{Construction of slow tourism industry chain}

Economic benefits, one of the three sustainable development goals, are essential in the slow tourism promotion. Mastering in slow tourism principles, building slow tourism environments, and leading tourism businesses to participate in slow tourism campaigns are the primary processes in the slow tourism promotion; however, the substantive contributions of tourism industry to the region was largely reduced because of the market support, competitiveness, and travel programs not being taken into account when developing community-based tourism (Coria and Calfucura 2012). In this case, tourism campaigns, economics, and other stakeholders should be closely linked when evaluating the economic development of the destination (Lucchetti and Arcese 2014).

Tourism industry integrates various resources, including accommodation, transportation, food and drink, entertainment, energy use, agriculture, culture, and ecology that the development would be advantageous to the societies and present the importance to environments (Gössling 2002; Lepp and Harris 2008). Accordingly, the slow tourism promotion needs to involve in all industries to the industry alliance for cross-selling and common economic interests.

The promotion of slow tourism industry alliance is preceded in three stages. In the concept construction and environment improvement stage, tourism businesses need to be persuaded to agree with the concept of slow tourism, and tourism departments have to do appropriate intervention and counseling to assist in the environment improvement and provide relevant subsidies (such as the change of electricity-reduction lightings or the purchase premium for electric vehicles). The points at this stage contain the concept construction, the training of operational skills, and the construction of environments conforming to the concept of slow tourism.

Second, tourism businesses meeting the requirements of slow tourism are integrated into the industry alliance to collaboratively conduct slow tourism campaigns. Such industry alliance should cover accommodation, food and drink, transportation, and entertainment to form a complete industry chain of slow tourism. The point at this stage lies in the operation of marketing tactics that it is the key stage to generate economic benefits and a primary stage for the consumer education. In order to achieve the actual economic benefits, it is necessary to select proper marketing tactics according to local characteristics so as to achieve the anticipated economic goals.

Finally, the participation extension and quality retention and control stage aims to gradually extend the participation in slow tourism and have local travel patterns base on slow tourism to ultimately promote slow tourism. In this case, when the slow tourism alliance is accepted in the market, extending the size of the 
industry chain and allowing more tourism industries joining in the slow tourism, marketing would shape the entire destination image and result in brand effects. What is more, quality retention and control of slow tourism is also the important work at this stage, aiming to extend the participation in slow tourism as well as to maintain the characters of slow tourism.

\section{A CASE STUDY OF SLOW TOURISM IN GREEN ISLAND, TAIWAN}

Each tourism pattern presents a suitable tourism environment. As the example of slow tourism, remote areas and the areas with inconvenient transportation are suitable for developing slow tourism (Conway and Timms 2010). Green Island with the area of $17 \mathrm{~km}^{2}$, located in the west rim of Pacific Ocean off southeastern coast of Taiwan, is an island surrounded with coral reefs (Figure 1). Rich marine resources around the island have it become an important fishery in the west rim of the Pacific Ocean. In regard to the geological conditions, Green Island, Taiwan, is just suitable for developing slow tourism. Being a new concept, cases on the practice of slow tourism are not many. The case of Green Island could be the empirical research on slow tourism promotion.

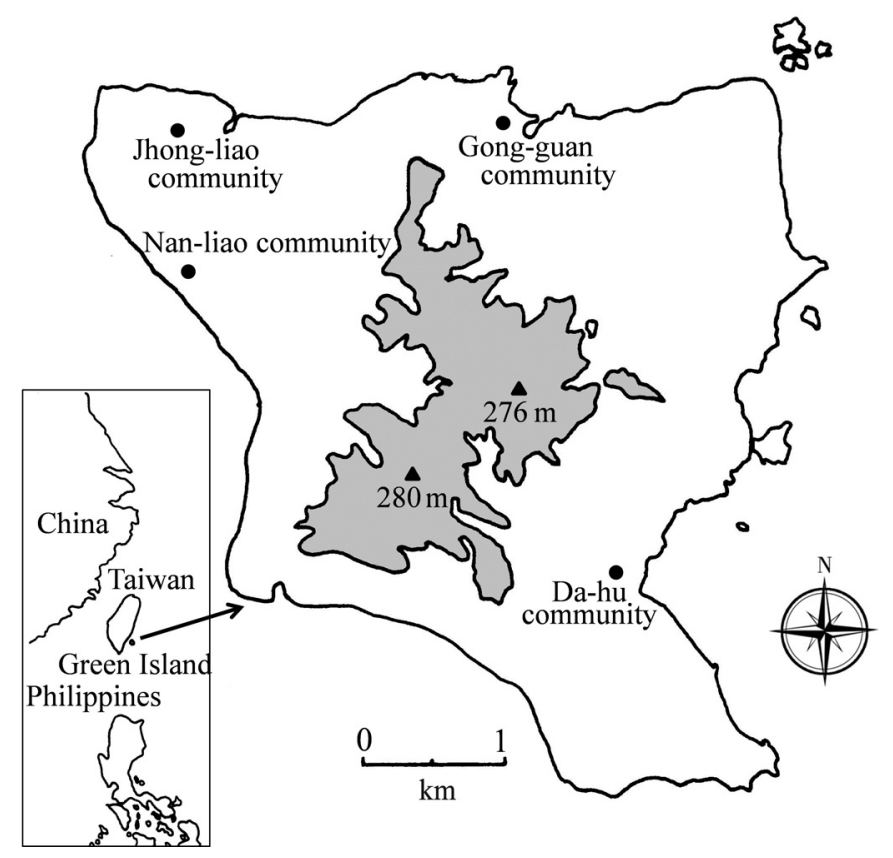

Figure 1. The location of the Green Island 
The immigrants from Taiwan in the $19^{\text {th }}$ century opened the development history in Green Island. Green Island used to center on agriculture and supplement with fishery to support life. Tourism industry developed in 1990 changed the economic style in Green Island. With the advance of tourism development, the increasing number of visitors to Green Island reached up to 0.4 million in 2004-2006. Although current number of visitors to Green Island maintains about 0.3 million, it still results in environmental impact on the small island with citizens less than 3,000 . The waste and noise caused by more than 2,300 motorcycles required for the visitors, the pollution on coral reef and the ocean resulted from water activities, and hermit crabs being lack of shells because of visitors picking up shells are the major environmental impact on Green Island. (Chao 2014).

In face of the social and environmental impact caused by large quantity of visitors, the citizens in Green Island start to reflect the specific methods for sustainable tourism. To improve the environmental pressure caused by mass tourism, volunteer tourism was introduced to Green Island in 2007 (Chao 2014a). In spite of the effectiveness, volunteer tourism was the niche tourism with operational skills that it could not comprehensively replace mass tourism. The concept of slow tourism was introduced to Green Island in 2013, and it has become an important alternative travel pattern currently.

\subsection{Effectiveness of slow tourism practice}

The slow tourism promotion in Green Island is commodified; with low-carbon transportation, low-carbon tourism businesses are combined to promote campaigns covering the concept of sustainable tourism, such as ecology, culture, and village, and local slow tourism operators lead the consumers for the two-day or three-day activities. According to the classification of slow travelers by Dickinson et al. (2011), most consumers participating in slow tourism in Green Island are Soft Slow travelers. In other words, such consumers emphasize the experiences in the activities, in addition to slowness and low-carbon.

Slow tourism in Green Island actually achieves the anticipated goal. More than 3,000 people were participating in slow tourism in Green Island in 2013, and the number of visitors doubled in 2014. In comparison with mass tourism, slow tourism reduced the carbon dioxide emission up to 12 tons in Green Island in 2014. Most slow travelers participated in the ecological conservation of "Giving back crabs a home", "Removing alien species of animals", and "Restoration of lilies" and learned the value of rural life by meandering the fish village. Such experiencing activities made the tour more unforgettable (Pine II and Gilmore 
2011); besides, they not only contributed to the environmental conservation at the destination, but also enhanced the value of tourism.

For travelers, the tourism value could be acquired by paying back to the communities through slow travel. For example, in the case of Green Island, the construction of inland highway results in crabs being run over by vehicles, on the way catadromy. An important appeal of slow tourism is to reduce environmental pressure caused by greenhouse gas emission with low-carbon transportation. The tourists "slowly" walk or ride bikes to reduce damage on crabs during the season of crabs laying eggs, and participate in the movement of escorting crabs crossing the streets during the catadromy. In the process, consumers leisurely travel around Green Island with slow tourism and savor the natural and cultural features in Green Island. The interpreters would enhance the idea of environmental protection so as to make the tour more meaningful.

A pith of slow tourism is the mental adjustment to savor the tourism process with leisure (Aall 2014). Long-stay slow travelers in Green Island also increased apparently in 2014. Such slow travelers spent more than a week in appreciating the natural landscape in Green Island, meandering along the coast, picking up floating objects on the ocean to made ornaments, participating in ecological conservation, and living with fishing villagers.

\subsection{Development of slow tourism - draft of promotion architecture}

The major problem in the slow tourism promotion appears in "how" to effectively facilitate the transformation of tourism patterns. For this problem, the operation process in Green Island might provide an effective reference. Figure 2 shows the architecture of slow tourism promotion in Green Island, which includes preparation stage and operational stage.

\subsubsection{Preparation stage}

Communications with the citizens are first preceded at this stage, in order to have the citizens and tourism employees accept the concept of slow tourism. The theory of collaborative planning, proposed by Healey, provides a favorable way to facilitate the communications with the citizens (Healey 1998). The theory of collaborative planning establishes the systems, assists in analyzing current situations, and guides future development through public forums. As volunteer tourism was promoted in Green Island several years ago, the concepts of environmental issues and local identification have shown certain consensus (Chao 


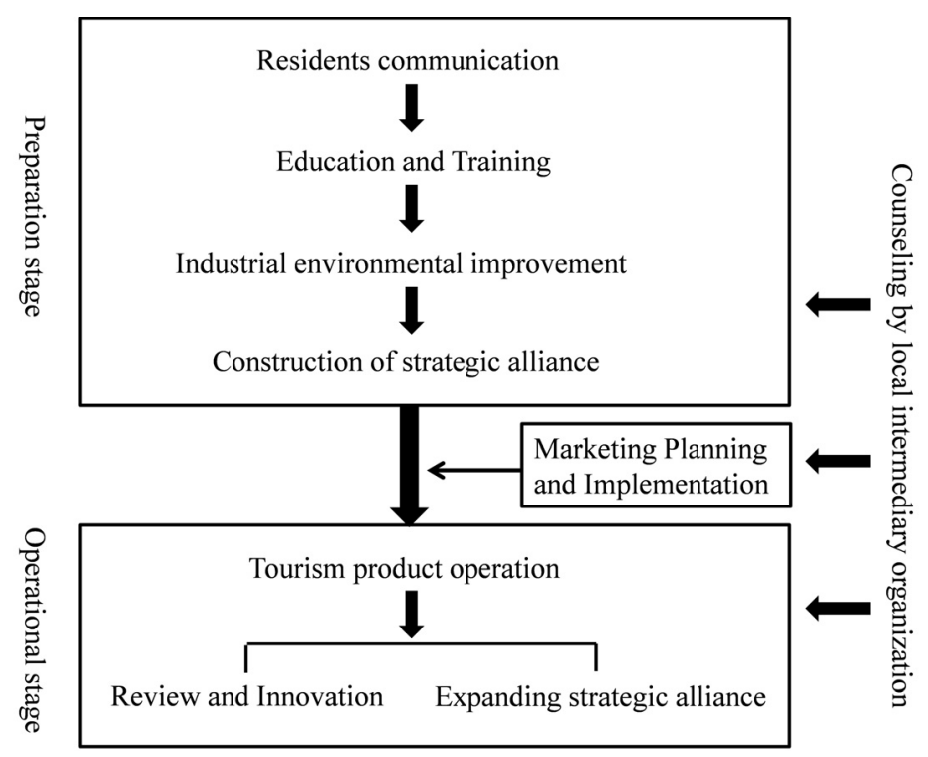

Figure 2. Slow tourism promotion architecture

2014a) that it would be easier to form the citizen consensus on slow tourism. The educational training of slow tourism operators and the improvement of industrial environments are the subsequent points. The participants in the educational training contain the businesses in the slow tourism industry chain (including accommodation, catering, diving and snorkeling, transportation rental, and craft industries) and local citizens who are expected to lead slow tourism (e.g. interpreters). As the slow tourism consumers in Green Island present the emphasis on activity experiencing, the training should cover how to design and plan specific slow tourism campaigns with experiencing connotation. In regard to the improvement of industrial environments, low-carbon and recreation are emphasized to build the spatial environment for slow tourism. Finally, the businesses participating in low-carbon tourism and the employees collaboratively sign to form the slow tourism industry chain for the common marketing propaganda.

Marketing is a primary work to generate economic benefits from slow tourism. With the propaganda of mass media and international tourism shows and the combination of tourism distributors (travel agencies, auto-sales network in chained convenience stores, and e-commerce websites), the slow tourism itineraries are commodified for domestic and international sales. A purpose of marketing is to import slow tourism consumers to generate the possibility of actual economic benefits. 


\subsubsection{Operational stage}

In addition to really operating the slow tourism campaigns, reviewing and innovating and extending the industry alliance are the key work at this stage. The travel products of any tourism patterns should be reviewed and introspected to make them perfect, and the original travel products are revised with innovative attitudes. Four slow tourism experiencing activities were preceded in Green Island in 2013, and 7 activities were increased in 2014; besides, with the operator training, the slow tourism process became more exquisite. What is more, the extension of industry alliance is also an important work at this stage. The extension of slow tourism industry could assist in shaping the tourism image at the destination. With the example of Green Island, 5 types of businesses and 28 tourism-related industries joined in the slow tourism alliance in 2013, while 7 types of businesses and more than 40 tourism businesses joined in the alliance in 2014.

Moreover, the assistance of an appropriate counseling organization is a key factor in regional slow tourism promotion for the proper development. Local intermediary organization is considered as the most suitable slow tourism counseling organization (Chao 2014b). The role of local intermediary organization is in between internal organizations and external organizations, as it could best understand the current situations at the destination. It therefore could seek for proper external resources from the government or enterprises and plan the work at each stage in the slow tourism operation procedure, according to the slow tourism operators and the environmental conditions at the destination. In regard to the case of Green Island, Society for Nature and Humanity, which has permanently concerned about the sustainable development in Green Island, plays the role of local intermediary organization in the slow tourism promotion process. In addition to introducing the concept of slow tourism, it also strives for the resources from the government and enterprises to help improve the industrial environment and provide necessary educational training. Furthermore, it also assists in the marketing planning and importing consumers. However, the actual operation of slow tourism and the derived economic benefits are acquired by the participants in the slow tourism industry alliance. That is, a local intermediary organization is a primary promoter and the key success factor in slow tourism.

\section{CONCLUSION}

Sustainable development is a common objective for human beings. In modern tourism markets, sustainable development plays a critical role and is the key factor in the operation of tourism market (Arcese et al. 2013). Moscardo and Murphy 
(2014) recently proposed a new concept of tourism, which could be utilized as a tactic for enhancing well-being, rather than a purpose of tourism itself. In fact, people are gradually restrained to time and environments by the rapid pace of life in the society and lose the leadership of life. Moscardo and Murphy's concept reminds of shaping the well-being of life in the tourism process.

"Slowness" is a resistance to the rapidly changing society as well as an important way to pursue well-being. Although slow tourism is originated from slow food movement, most importantly, it is the extension of slow life value. In the process of savoring tourism (Aall 2014), the relationship between people and environments is introspected through slow attitudes and thinking that the pith of various types of sustainable tourism, including ecotourism, pro-poor tourism, volunteer tourism, agricultural tourism, heritage tourism, and community tourism, is naturally absorbed. The concept of Holistic Umbrella therefore is used for describing the role of slow tourism (Conway and Timms 2010), i.e. to regard slow tourism as the complex of contemporary sustainable tourism.

Nevertheless, the theoretical concepts of any tourism patterns might be proven from academic studies, but distinct dilemmas and challenges are likely encountered in the operation process. Slow tourism experiences the same situations that operational challenges still exist in slow tourism despite that there is clear interpretation of the connotation (Mair 2011; Bâc 2013). Such slow tourism challenges could be solved through the education of operators and consumers and the construction of industry alliance.

With the research on the slow tourism promotion in Green Island, the promotion architecture is drawn up in this study. The slow tourism promotion could be preceded at two stages. The preparation stage focuses on the communications with the citizens, the improvement of industrial environments, and the construction of industry alliance. The marketing is operated right after the preparation stage to import slow tourism consumers. The operational stage stresses on the review and innovation of slow tourism and the extension of industry alliance. In the promotion process, the selection of a proper counseling organization is a key factor in the effectiveness of slow tourism. Local intermediary organization is the most suitable counseling organization (Chao 2014b), as it could integrate resources from internal and external organizations to develop the maximal benefits of slow tourism.

The concept of slow travel is gradually accepted in Taiwan, but sufficient cases are required for making slow travel a systematic model. Green Island is one of the promotion areas for slow travel (Tourism Bureau of Taiwan 2014). From the research results, slow travel indeed is a feasible plan for sustainable tourism in a small island. Nevertheless, although Green Island is isolated by the ocean with rich natural resources, a small area, and few citizens, the premise is that 
the consensus is likely achieved through community participation as the citizens are mutually acquainted. It still needs more research to prove such a model being applicable to non-island environments. Jigang and Jiuxia (2007) mentioned that the distinct environments, systems, and societies in the tourism development between China and western societies resulted in the difference in participation. However, the policies and systems in Taiwan are close to western societies that the present tourism development in Taiwan is similar to that of western societies. Consequently, the case study on slow travel in Green Island might be an attempt or a mirror for western societies. From the promotion of slow travel in Green Island, this study focuses on the system and citizen participation. Nonetheless, visitors are the consumers in tourism industry. Although the visitor perception of slow travel participation in the observation process could be found, the psychological measurement needs to be proceeded through quantitative research. In this case, quantitative research would be inevitable in order to confirm the effects and value of slow travel from the aspect of visitors.

Slow tourism is an emerging tourism pattern and a good way to promote sustainable development through tourism campaigns. Nevertheless, the selection of slow tourism destinations appears certain restrictions; remote areas and the areas with inconvenient transportation are the most suitable destinations for developing slow tourism (Conway and Timms 2010). So far, there are not many empirical cases on slow tourism, and the slow tourism promotion in Green Island reveals favorable effectiveness. As a consequence, the slow tourism promotion architecture drawn in this study, under the premise of the destination conditions being suitable for developing slow tourism, could be the reference of slow tourism development.

\section{ACKNOWLEDGEMENT}

The financial support of the Ministry of Science and Technology (102-2621-M214-001) for this study is gratefully acknowledged.

\section{REFERENCES}

Aall, C. (2014). Sustainable tourism in practice: promoting or perverting the quest for a sustainable development? Sustainability, 6, 2562-2583.

Arcese, G., Lucchetti, M.C. and Merli, R. (2013). Social life cycle assessment as a management tool: Methodology for application in tourism. Sustainability, 5, 3275-3287.

Bâc, D-P. (2013). Sustainable tourism and its forms - A theoretical approach. Annals of the University of Oradea, Economic Science Series, 22(1), 759-767. 
Beeton, S. (2006). Community Development through Tourism. Australia: Land Links.

Ceron, J.P. and Dubois, G. (2007). Limits to tourism? A backcasting scenario for sustainable tourism mobility in 2050. Tourism and Hospitality Planning \& Development, 4(3), 191-209.

Chang, A. (2014). Effects of tourism image and experiential value on revisit intention in tourism industry. Acta Oeconomica, 64(Supplement 2), 289-301.

Chao, R-F. (2014a). Volunteer tourism as the approach to environmental management - a case study of Green Island in Taiwan. Journal of Environmental Protection and Ecology, 15(3A), $1377-1384$.

Chao, R-F. (2014b). Innovation strategies of local intermediary organizations for environmental protection: a case study of Green Island, Taiwan. The International Journal of Organizational Innovation, 7(2), 87-97.

Conway, D. and Timms, B.T. (2010). Re-branding alternative tourism in the Caribbean: The case for 'slow tourism'. Tourism and Hospitality Research, 10(4), 329-344.

Coria, J. and Calfucura, E. (2012). Ecotourism and the development of indigenous communities: The good, the bad, and the ugly. Ecological Economics, 73, 47-55.

Dickinson, J.E. and Lumsdon, L. (2010). Slow Travel and Tourism. London: Earthscan.

Dickinson, J.E., Lumsdon, L.M. and Robbins, D. (2011). Slow travel: issues for tourism and climate change. Journal of Sustainable Tourism, 19(3), 281-300.

Djeri, L., Armenski, T., Jovanović, T. and Dragin, A. (2014). How income influences the choice of tourism destination? Acta Oeconomica, 64(2), 219-237.

Dossey, L. (1982). Space, Time and Medicine. Boston: Shambhala Publications.

Erhart, S. (2008). Motorist conquest in big cities: The case of Budapest. Acta Oeconomica, 58(1), $1-28$.

Fu, H.W. and Yeh, S.P. (2014). Exploring correlations among tourism characteristics, visitor behavior intention, and customer satisfaction. Acta Oeconomica, 64(Supplement 2), 99-110.

Gardner, N. (2009). A manifesto for slow travel. Hidden Europe, 25, 10-14.

Giudici, E. and Dessì, S. (2011). A new approach is born: the slow philosophy via agri-tourism. Review of Business Research, 11(5), 85-94.

Godbey, G. (2003). Leisure in Your Life: An Exploration. Pennsylvania: State College.

Golusin, M. and Ivanović, O.M. (2009). Definition, characteristics and state of the indicators of sustainable development in countries of Southeastern Europe. Agriculture, Ecosystems and Environment, 130, 67-74.

Gössling, S. (2002). Global environmental consequences of tourism. Global Environmental Change, 12(4), 283-302.

Gössling, S., Hall, M., Lane, B. and Weaver, D. (2008). Report: The Helsingborg statement on sustainable tourism. Journal of Sustainable Tourism, 16(1), 122-124.

Hall, C.M. (2006). Culinary tourism and regional development: From slow food to slow tourism? Tourism Review International, 9(4), 303-306.

Hatipoglu, B., Ertuna, B. and Sasidharan, V. (2014). A referential methodology for education on sustainable tourism development. Sustainability, 6, 5029-5048.

Healey, P. (1998). Building institutional capacity through collaborative approaches to urban planning. Environment and Planning, 30(9), 1531-1546.

Heitmann, S., Robinson, P. and Povey, G. (2011). Slow food, slow cities and slow tourism. In Robinson, P., Heitmann, S. and Dieke, P., eds, Research Themes for Tourism. Wallingford: CABI, $114-127$.

Hetzer, N.D. (1965). Environment, tourism, culture. Links, 1(2), 1-3.

Honoré, C. (2010). In Praise of Slow. London: Hachette. 
Jigang, B. and Jiuxia, S. (2007). Differences in community participation in tourism development between China and the West. Chinese Sociology \& Anthropology, 39(3), 9-27.

Katircioglu, S. (2009). Testing the tourism-led growth hypothesis: The case of Malta. Acta Oeconomica, 59(3), 331-343.

Lepp, A. and Harris, J. (2008). Tourism and national identity in Uganda. International Journal of Tourism Research, 10(6), 525-536.

Levine, R. (1997). A Geography of Times: The Temporal Adventures of a Social Psychologist. New York: Basic Books.

Li, Y.M., Yang, C.Y., Kuo, Y.H. and Hung, R.Y. (2014). Exploring green service quality elements for international tourist hotels in Taiwan from the aspect of two-dimensional quality model. Acta Oeconomica, 64(Supplement 2), 111-125.

Lucchetti, M.C. and Arcese, G. (2014). Tourism management and industrial ecology: A theoretical review. Sustainability, 6, 4900-4909.

Lumsdon, L.M. and McGrath, P. (2011). Developing a conceptual framework for slow travel: a grounded theory approach. Journal of Sustainable Tourism, 19(3), 265-279.

Mair, J. (2011). Book review: Slow travel and tourism. Australian Journal of Environmental Education, 27(1), 196-197.

McGehee, N.G. and Andereck, K. (2009). Volunteer tourism and the "voluntoured": the case of Tijuana, Mexico. Journal of Sustainable Tourism, 17(1), 39-51.

Molz, J.G. (2009). Representing pace in tourism mobilities: staycations, slow travel and The Amazing Race. Journal of Tourism and Cultural Change, 7(4), 270-286.

Moscardo, G. and Murphy, L. (2014). There is no such thing as sustainable tourism: Re-conceptualizing tourism as a tool for sustainability. Sustainability, 6, 2538-2561.

Parkins, W. (2004). Out of time: Fast subjects and slow living. Time Society, 13(2/3), 363-382.

Peeters, P. and Schouten, F. (2006). Reducing the ecological footprint of inbound tourism and transport to Amsterdam. Journal of Sustainable Tourism, 14(2), 157-171.

Pine II, B.J. and Gilmore, J.H. (2011). The Experience Economy. New York: Harvard Business Press.

Reisch, L.A. (2001). Time and wealth: The role of time and temporalities for sustainable patterns of consumption. Time Society, 10(2/3), 367-385.

Reyes-Garcia, V., Ruiz-Mallen, I., Porter-Bolland, L., Garcia-Frapolli, E., Ellis, E.A., Mendez, M-E., Pritchard, D.J. and Sanchez-Gonzalez, M-C. (2013). Local understandings of conservation in Southeastern Mexico and their implications for community-based conservation as an alternative paradigm. Conservation Biology, 27(4), 856-865.

Timms, B.T. and Conway, D. (2011). Slow tourism at the Caribbean's geographical margins. Tourism Geographies, 14(3), 396-418.

Tourism Bureau of Taiwan (2014). The focus of tourism policy in Taiwan. Available at: http://admin.taiwan.net.tw/public/public.aspx?no=122 (Accessed 28 Oct. 2014).

Volkery, A., Swanson, D., Jacob, K., Bregha, F. and Pinter, L. (2006). Coordination, challenges, and innovations in 19 National Sustainable Development Strategies. World Development, 34(12), 2047-2063.

Weaver, D. (2006). Sustainable Tourism: Theory and Practice. Oxford: Butterworth-Heinemann.

Woehler, K. (2004). The rediscovery of slowness, or leisure time as one's own and as self-aggrandizement? In Weiermair, K. and Mathies, C. (eds), The Tourism and Leisure Industry: Shaping the Future. New York: The Haworth Hospitality Press, 83-92.

World Tourism Organization Network (2014). Sustainable development of tourism. [online] Available at: http://sdt.unwto.org/en/content/about-us-5 (Accessed 17 May 2014). 